\title{
TEAM HEALTH: A MEASURED APPROACH TO COLLECTIVE LEARNING
}

\author{
Anthony Muñoz ${ }^{1}$, Jean Laurent ${ }^{2}$, and Chris Dierks ${ }^{3}$
}

\begin{abstract}
This paper addresses the problem in failing to identify, measure, and monitor the human component (i.e. participant satisfaction) in the delivery of a lean construction project. Traditional measures of lean construction fail to represent or provide insightful commentary to the lengths they measure. The authors of this paper present the team health assessment as a tool that DPR Construction has used to better identify and provide measurement to otherwise unquantifiable indices of a project's performance. With this tool, project teams are able to facilitate a disciplined approach to learning, learning from the team and as a team, throughout the entire life cycle of design and construction. This added awareness could then be used to better identify and optimize value from a holistic viewpoint.
\end{abstract}

\section{KEYWORDS}

Language action perspective, benefits realization, action learning, moods, collective learning.

\section{INTRODUCTION}

This industry paper is a compliment to Cleary and Muñoz (2018) Reaping the Rewards of Production Tracking. In that discussion, morale was identified as an unquantifiable index of a project's success. The value of morale was unable to be substantiated beyond qualitative statements as expressed by several of the subject project's participants. As it was in that case, these statements are often retrospective and do little to influence a project throughout its delivery. This lapse was later identified as an opportunity for continued research.

The body of this paper observes DPR Construction's implementation of a team health assessment on several of its projects to better identify and provide measurement to otherwise intangible indices of a project's performance such as participant satisfaction. As derived from the feedback of two Southern California healthcare project teams as well as from that of an Integrated Project Delivery team who recently completed campus improvements at Penn State University, the objective of this paper is to present what

Healthcare Project Manager, DPR Construction, San Diego, CA 92122, USA, anthonym@dpr.com

Project Engineer, DPR Construction, Newport Beach, CA 92660, USA, jeanl@dpr.com

Lean Manager, DPR Construction, Ft. Lauderdale, FL 33301, USA, chrisd@ dpr.com 
benefits were gained from measuring and monitoring team health, in addition to the more common lean construction measurements of productivity, in efforts to optimize value for all stakeholders.

\section{METHODOLOGY}

This industry paper is the product of its authors' experiences through observation in action learning. Through action learning, the researcher is a participant and the subject of research is change to processes in which they are involved (Westbrook 1995). Responsible subject involvement in some real and complex problem in instrumental to achieving the intended improvement (Revans 1982). This concept is based on the premise that learning emanates from reflection followed by action to solve real problems where reflection and discussion occur in small groups (McGill and Beaty 1995). An expository was additionally conducted to qualify the problem objectively through existing literature.

\section{BACKGROUND}

\section{THE LEAN MACHINE}

Drawing from Japanese manufacturing management principles, most notably that of Toyota, lean production systems are loosely defined about continuous improvement, decentralized decision making, waste elimination, and the optimization of resource utilization (Womack et al.1990). In these systems, processes and thereby organizations are finely tuned to maximize value. This concept was foundational to Howell's response to the question, "What is lean construction?" as presented at the 1999 IGLC Conference holdings (Howell 1999). This discussion further provided that the defining features of lean construction include predetermined objectives to produce the greatest performance for a customer at the project level, from design to delivery, through the application of production control.

Detractors to this new construction philosophy criticized the western exploitation of eastern concepts, claiming the transposition of the perceived positives while altogether ignoring the inherent drawbacks. Green (1999) decried that, under the guise of this philosophy, organizations become merely machines in pursuit of predetermined objectives. Within these machines, human resources are cogs that are only necessary to achieve organizational objectives. This was neither a new nor unique protest of lean management principles. Kamata (1982) describes how the success of Toyota as an organization was paired with significant personal deprivation of the workforce. While this process may produce the greatest value for the customer, some have argued that this value is at the expense of undue stress and exploitation of the worker (Mehri 2006).

Howell (1999) was not silent on addressing the human component of project management; however, it is considered secondary to production management. He maintains that value can be more efficiently reflected and realized by measuring the performance of the planning system. This conclusion is constrained in that it fails to consider what happens to the machine when the cog that is human resources is the root of variation. 


\section{The Problem...or The OPPORTunity}

Green (1999) remarks that Japanese manufacturing organizations, in their implementation of lean philosophies, have historically wielded a great negotiation strength over workers in the threat of uprooting operations elsewhere if the workforce refuses to conform. While this is a threat on a macro level, on the micro or project level, as it is in construction, the opposite is true; worker conformance is the driver of a project's strength.

As a foundation to the Lean Project Delivery System (LPDS), a project must determine stakeholder purposes (perceptions, desires, needs and values), translate these purposes into processes, and design a system for development (Ballard and Zabelle 2000). The execution of a project is then the iterative implementation of this three-component cycle. It serves to reveal the consequences of stakeholder desires and identify the response to variation necessary throughout delivery as compared to what may have been originally conceived. LPDS utilizes "work structuring" in both qualifying and quantifying processes and systems. This planning mechanism is used to identify and create flow amongst the various activities involved through specifying how and when work is to be done within the confines of the project schedule (Ballard 1999). Ballard and Howell (2003) propose that schedules are products of work structuring that specify goals and the handoffs required to achieve those goals. Typically, these handoffs are between contractors (Howell et al. 1993). "Contractor" can be defined as the person or collective that arranges to supply materials or workers for building. It can then be theorized that the successful delivery of a lean construction project is dependent on the project team's responsiveness to the evolving perceptions, desires, needs and values of the individuals that comprise it.

\section{A Solution in Concept}

Holding that project success is driven by a project team's awareness to the fluctuating perceptions of its working individuals, DPR Construction proposes a team health assessment to provide metrics to the qualitative indices that have been previously identified as a challenging component to objectively measure and monitor. The concept of a team health assessment is not novel; however, its interpretation and documented application in the design and construction industry appears to be new ground.

\section{Agile Beginnings}

The concept of a team health assessment is rooted in Agile methodology. The Agile approach was developed by Bernie Dimsdale, John von Neumann, Herb Jacobs, and Gerald Weinberg in the late 1950's as a method of building software that was flexible and efficient. This approach was formally reprogrammed in 2001 when a group of 17 software development professionals met to draft the Manifesto for Agile Software Development (altexsoft, 2019).

The first value of the Agile Manifesto is to prefer "Individuals and interactions over processes and tools." This Manifesto and the Agile methodology have since evolved from managing software development into becoming a more universal project management approach. For example, the team health assessment, also referred to as a maturity model, is a tool that has transcended across multiple industries. 


\section{Modelling Behaviour}

Fowler (2014) defines the maturity model as a tool that helps people assess the current effectiveness of a person or group of people and supports figuring out what capabilities they need to acquire to improve performance. Working with these models begins with assessment to determine the current level of performance. With this measure, one is better able to identify what capabilities may be needed or require improvement. The model effectively qualifies and quantifies user perception, providing structure to what could be a more complex process. This generic model has taken many formats, often as an extension of the personality and culture of the organization employing it. One model that has seen wide acceptance for its simplicity in use is the Spotify Team Health Check.

Spotify is a digital music, podcast, and video streaming service provider. Kniberg (2014) outlines the approach to the Spotify Team Health Check. This starts with organizing a one to two-hour workshop with the squads, or functional teams, to hold a face-to-face conversation around the different health indicators. To facilitate this, there is a physical deck of "Awesome Cards." Each card includes one health indicator with an "Example of Awesome" and "Example of Crappy." For each question, the squad is asked to discuss if they are closer to "awesome" or closer to "crappy." Measures for each of the indices are then visually summarized using a colour code. Basic workshop techniques (dot voting, etc.) are used to reach consensus about which colour to choose for that indicator. The definition of the colours is loosely based around the following:

- Green - no need for major improvement currently.

- Yellow - flawed, but not critically important to address immediately.

- Red - this "really sucks" and must be immediately assessed for improvement.

Summarizing responses in this way provides a visual trigger to identify areas that require greater retrospective. Between team health checks, the tallies are used as a visual management tool to promote targeted areas of improvement. Figure 1. is representative of this summary and provides specific examples of three of the indices used. Additional detail is being included in the Appendices.

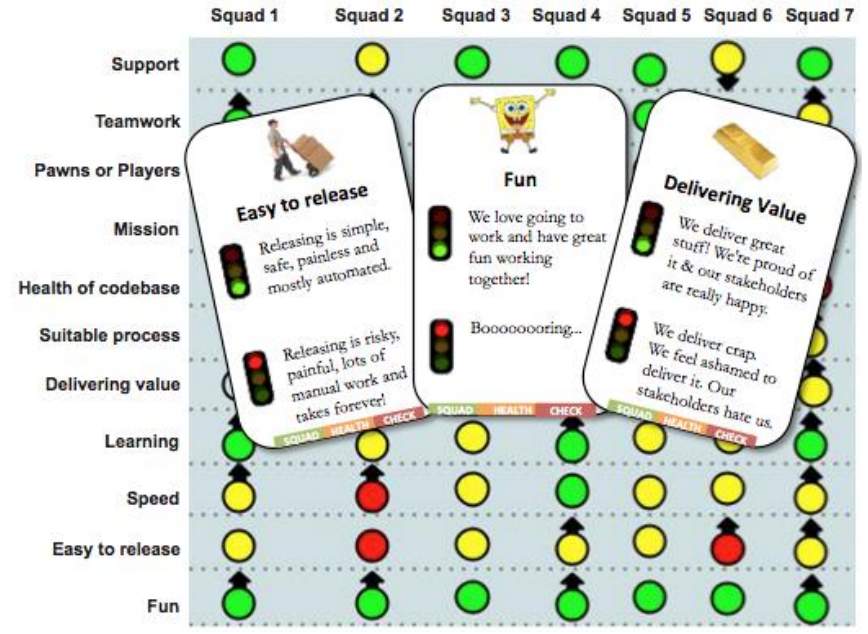

Figure 1: Spotify Squad Health Check Model Summary

\section{AUTHORS' EXPERIENCE}

\section{A Solution in Practice}

DPR Construction employs an approach similar to the Spotify Team Health Check. However, while in-person discussions are preferable, a survey approach has been found to be more effective given the often satellite locations of participants on a construction project. 
This is done by inviting project stakeholders to participate in a regular reflection on overall project effectiveness through survey responses. The questionnaire is a collective of statements that support and measure the perceived alignment in meeting the team defined conditions of satisfaction. Figure 2. is representative this survey format.

\begin{tabular}{|c|c|c|c|}
\hline KPI & & $\begin{array}{l}\text { HELP US IMPROVE, PROVIDE HONEST FEEDBACK } \\
\text { Completely Anonymous }\end{array}$ & $\begin{array}{l}\text { SCORE } \\
1 \text { to } 5\end{array}$ \\
\hline COMMUNICATION & 1 & $\begin{array}{l}\text { Information is requested and transmitted in a timely manner. } \\
\text { Right information to the right person. }\end{array}$ & \\
\hline COMMITMENT & 2 & $\begin{array}{l}\text { The Team makes reliable commitment to each other to support } \\
\text { the project schedule. }\end{array}$ & \\
\hline PROJECT DOCUMENTS & 3 & $\begin{array}{l}\text { The Team successfully utilizes the design documents and BIM } \\
\text { to execute the coordinated work and communicates back to the } \\
\text { design team. }\end{array}$ & \\
\hline INNOVATION & 4 & $\begin{array}{l}\text { I am encouraged to seek out and bring innovative ideas, } \\
\text { solutions, and processes to the project. }\end{array}$ & \\
\hline COLLABORATION & 5 & $\begin{array}{l}\text { The team is effectively collaborating to ensure all issues are } \\
\text { brought up as soon as they arise and dealt with quickly. }\end{array}$ & \\
\hline VISUAL MANAGEMENT & 6 & $\begin{array}{l}\text { Team successfully utilizes visual control methods-dashboards, } \\
\text { A3's, logs, drawings, etc. }\end{array}$ & \\
\hline AWARENESS & 7 & $\begin{array}{l}\text { I fully understand the construction schedule for the project and } \\
\text { when my response is critical to the schedule. }\end{array}$ & \\
\hline QUALITY & 8 & $\begin{array}{l}\text { The team defined clear and measurable definable features of } \\
\text { work. Quality expectations of the projects are understood and } \\
\text { implemented by all. }\end{array}$ & \\
\hline TRUST & 9 & $\begin{array}{l}\text { Team members demonstrate trust and respect across all levels } \\
\text { of the team. }\end{array}$ & \\
\hline LEARNING & 10 & $\begin{array}{l}\text { The project team embraces an open, collaborative learning } \\
\text { process and implement lessons learned. }\end{array}$ & \\
\hline $\begin{array}{l}\text { END USER } \\
\text { SATISFACTION }\end{array}$ & 11 & The Team values End User and Member experience as a priority. & \\
\hline SAFETY & 12 & Do you feel safety is demonstrated as a top priority? & \\
\hline $\operatorname{cost}$ & 13 & $\begin{array}{l}\text { Are all team members consistently integrating project budget } \\
\text { and forecast in their daily decision making? }\end{array}$ & \\
\hline PARTICIPATION & 14 & $\begin{array}{l}\text { Do you feel openly that you have a voice and are an important } \\
\text { member of this project team? }\end{array}$ & \\
\hline TIME MANAGEMENT & 15 & Are we spending time in meetings that add value? & \\
\hline ENJOYMENT & 16 & Would you chose to work with this team again? & \\
\hline \multicolumn{4}{|c|}{17 What is the one thing you would like to see improved? (Can be anything) } \\
\hline
\end{tabular}

Figure 2: Example of Team Health Assessment Questionnaire 
Respondents are asked to provide a quantitative response to the statements that are provided. Figure 3. is representative of the Likert-type scale on which these values are measured. Actual verbiage for each response scale is specific to the KPI it measures. This particular scale is as would be presented to measure KPI No. 9: Trust.

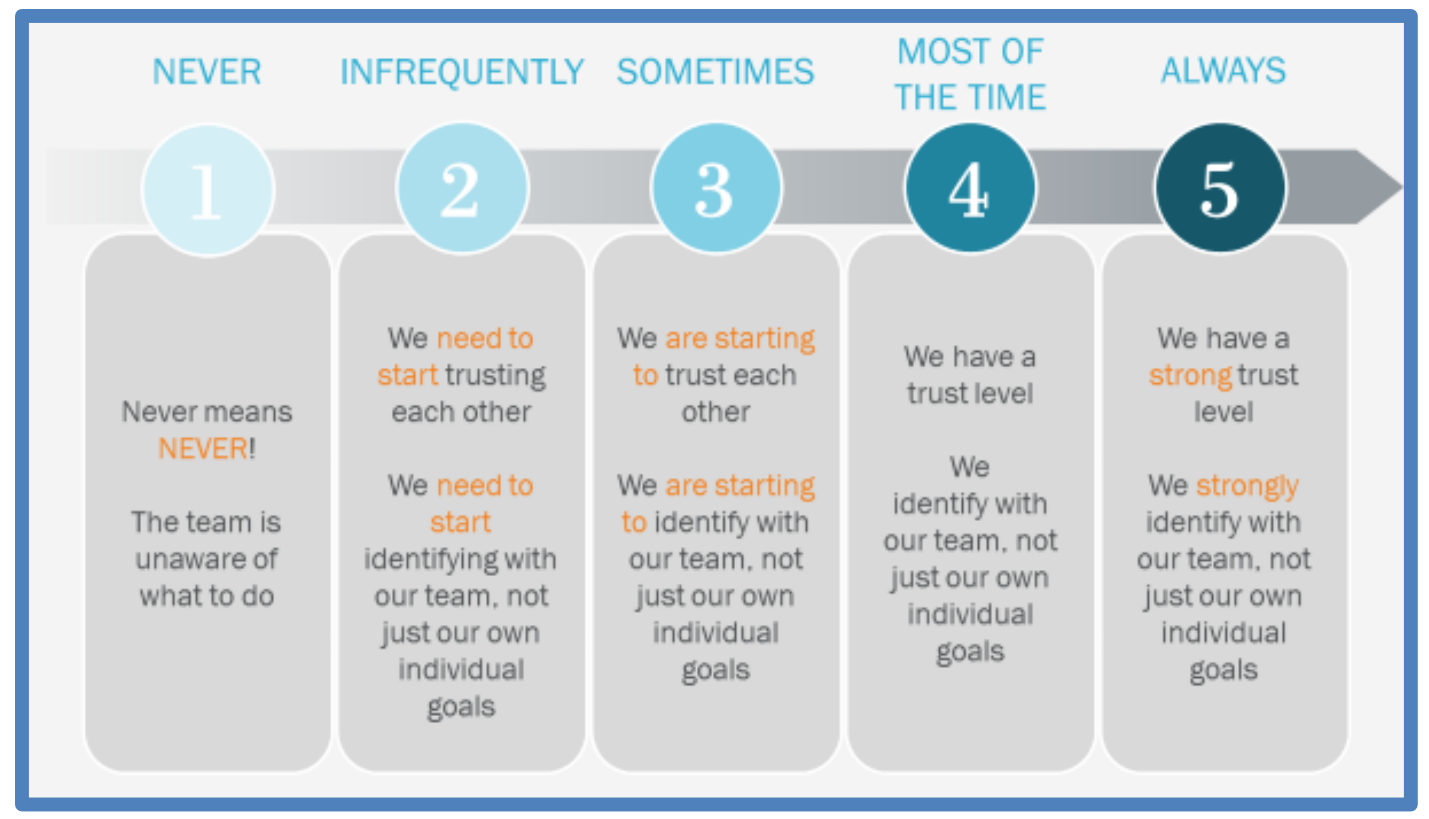

Figure 3: Team Health Assessment Likert-type Scale as Presented for KPI No. 9: Trust

Project teams have differed in the interval in which the reflections are facilitated, most commonly monthly, as well as in the delivery tool used to gather responses. However, the nature and presentation of statements have been similar and results tabulated in a normal format. Figure 4. illustrates the measuring wheel used to communicate the weighted response to each statement. This standard report makes future comparison over time and between projects more easily comparable. Additionally, it allows a dynamic platform to compare current response values to trending response values. This information is reviewed as regularly as the assessment is conducted. The more regular the assessment is conducted, the more live the data is. Ultimately, this trove of information can be used as a key performance indicator in a multitude of qualitative fields as determined by the assessment statements.

As is often the case in Agile methodologies, the best value of this tool comes more from the conversation that it generates than with the actual results (Kniberg 2014). As such, this section observes three project teams and their reflection on the value of the team health assessment as a tool - as opposed to highlighting specific survey results. However, excerpts from actual surveys and their resulting metrics have been included for reference in the Appendices. 


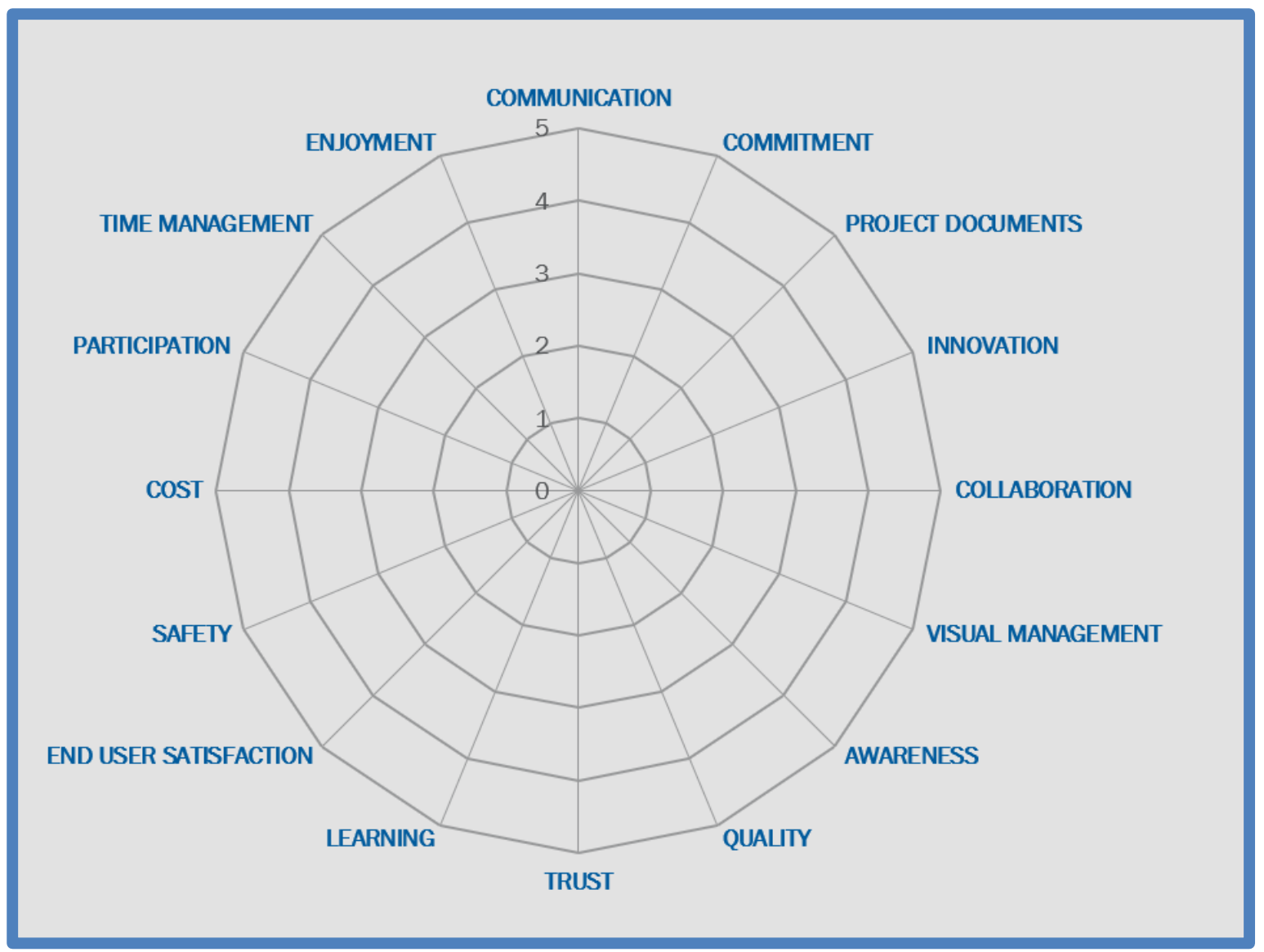

Figure 4:: Team Health Assessment Measuring Wheel

\section{Project \#1 Summary}

The first of the three projects observed includes phased upgrades of an existing medical campus in Southern California. The project intent is to relocate and construct a new clinical laboratory including blood bank and part of lab administration in approximately 6,000sf of vacant space on the basement level; relocate and construct a new pathology department, including testing and administrative functions, in approximately 2,700sf of space vacated by the clinical laboratory; and expand the blood draw area into the remaining space vacated by the clinical laboratory.

The nature of this work, in and about an existing and operating healthcare campus, is predisposed to be high stress given the close quarters and life critical surroundings. To that ends, creating and executing flow to minimize disruptions is imperative.

\section{Perceived Value}

Amongst other issues that presented throughout conducting the team health assessments, project representatives noted that this platform helped to identify the significance of external influences on project success. More specifically, a collective of survey responses identified an underlying dissatisfaction with the timeliness of constraint identification and expectation of flexibility to resolve. Given the nature of construction within existing 
conditions, issues tend to first present at the time walls are opened if preconstruction surveys are not achievable. Moreover, construction activities such as electrical power shutdowns for equipment replacement require intensive coordination between multiple parties. In these instances, forecasting coordination meetings is challenging. While all parties had expectations of the unexpected, finding time to huddle became the source of growing stress amongst team members. The root cause was identified to be a lack of understanding of each other's project demands on top of their external commitments (outside of the project scope).

As a result, the team implemented two initiatives. The first was a shared calendar so that team members would have a better understanding of each other's overall demands on their time. The second was a Process Review Meeting to identify required deliverables by each partner to streamline these coordination efforts. These simple adjustments helped to alleviate stresses that, if had gone unchecked, could have lessened the quality and effectiveness of these constraint removal efforts by bringing alignment to demands and providing clear expectations of success.

\section{Project \#2 Summary}

The second of the three projects observed also includes upgrades to an existing medical campus in Southern California, although in a different location than the first. The project includes tenant improvements consisting of a complete renovation of a 1-story over basement with a change of occupancy and use from vacant to ambulatory health care, including outpatient surgery and procedure suites, 39-bay pre-operative holding and postanaesthesia recovery suites, sterile processing and complimenting support services. Additionally, the project includes improvements to site parking and patient drop-off areas.

\section{Perceived Value}

Again, the nature of working in an existing healthcare campus is predisposed to be a stressful environment. To that ends, creating and executing flow to minimize disruptions is imperative; this was facilitated using the Last Planner System. Despite acceptable PPC scores as tracked through a Weekly Work Plan report out, a collective of assessment responses identified a growing dissatisfaction with the overall management of the project plan at the early stages of execution. Through further dialogue, there was a sentiment that the Phase Pull Planning process specifically was too detailed. This extraneous effort (for this level of development) incumbered the flow of communication to crews.

This conversation led to restructuring the Last Planner sessions to place a greater reliance on Look Ahead Planning into Weekly Work Planning. This was facilitated by providing additional training to team members on the Last Planner System, focusing on required levels of flow and commitment at each stage. This index provided by the team health assessment provided insight to a potential constraint before it materialized in production tracking.

\section{Project \#3 Summary}

The third of the three projects observed was a recently completed modernization of the Agricultural Engineering Building at Penn State University (PSU). The two major components of this 93,500 sf project include: 
- The modernization of the existing Charles Klauder Building. Built in 1938, the historic building required major upgrades to meet safety and energy standards, as well as end-user needs.

- The demolition of a 1960's addition to the building. In its place, the project team constructed a replacement building, designed to match existing campus architecture.

The Agricultural Engineering Building houses the Department of Agricultural and Biological Engineering departments, including four multi-purpose classrooms, more than 30 comprehensive research and teaching labs, and several conference rooms and collaboration lounges. Agricultural engineering, with its broad range of study, required facilities to include complex bio-chemistry laboratories, machine shops, integrated hydrology-hydraulics laboratories and a new centralized fermentation laboratory.

This was PSU's first project using a poly-party Master Integrated Project Delivery (IPD) Agreement. The five signatory partners consisted of the Owner, General Contractor, A/E firm, Electrical Trade Partner, and a Mechanical \& Plumbing Trade Partner.

\section{Perceived Value}

True to the IPD culture, the PSU IPD team sought a way to measure its performance and whether it was truly achieving the defined Conditions of Satisfaction and Value Statement. The implementation of the team health assessment met that objective in bringing the team members together to reflect on past performance, commit to improvements and gain consensus on the path forward. For these reasons, the PSU IPD team considered the team health assessment as a primary driver for project success.

Each month, throughout both design and construction, the project team allocated a minimum of one hour in one of its Big Room Meeting's agenda to reflect on the results of that month's team health assessment. The data was solicited, compiled and reviewed on the same day to ensure the most current information was reflected and acted upon. Intentionally, the longest part of the reflection was centred around one specific question, "What's one thing you would like to see improved? (Can be anything)". Some of the team's best innovations and efficiency improvements came from the resulting dialogue.

In one month in particular, responses strongly suggested that the MEP Cluster was not functioning as a cohesive unit. One contributing cause was identified to be that the cluster had too many attendees in its regular meetings. As such, planning sessions were constrained at a level that remained inclusive of all attendees or the discussions became too narrow for the larger group and certain partners became disengaged as a result. Either consequence resulted in inefficiencies or were otherwise detrimental to the project's wellbeing. The outcome of that month's team health assessment reflection provided that a sub cluster or Project Implementation Team (PIT), in this instance for the electrical partners, would address this concern and provide greater value. This PIT, consisting of four team members, would later become the highest preforming cluster on the project. Measurable outcomes for this PIT include a $4 \%$ costs savings as compared to its respective target cost. This was done through an expeditious, yet efficient design and modelling process which also yielded a 22-day schedule savings as compared to the original planned durations. This approach also supported DPR Construction's mantra, "Respect the Individual." By identifying a single individual to report up, the created additional capacity 
for the remaining three members of the PIT to repurpose and provide greater value in other areas of the project.

With the resulting success of creating the Electrical PIT through the re-organization of the MEP Cluster, the IPD team was inspired to observe the remaining clusters for opportunity that they too could be optimized. Three additional sub-clusters were created as a result. Given that most of the IPD team was not local, this simple change to team structure optimized and focused each individual's efforts in the right place, providing for the opportunity to offer the greatest value where and as needed. The team feels strongly that without the team health assessment and the purpose driven dialogue, it would have not recognized and benefited from these opportunities for improvement.

\section{CONCLUSIONS}

\section{REFLECTION}

Through observing the experiences of two Southern California healthcare project teams as well as the PSU IPD project team, this paper presents the value in utilizing a team health assessment to better identify and provide measurement to otherwise unquantifiable indices of a project's performance. Both project case studies provide credence to using this new rubric for identifying and monitoring key performance indicators not captured with traditional lean construction tools.

This holistic perspective is becoming increasingly more common in providing a more inclusive answer to the question, "what is lean construction?" Seed (2010) provides that lean construction is a respect and relationship-oriented production management-based approach to project delivery. Furthermore, Mossman (2018) has observed that by 2013, Howell's definition softened to include "An application to construction of a management philosophy defined by the ideal it pursues, the principles followed in pursuit of the ideal, and the methods used to implement the principles." Ultimately, by measuring not only the process, but also the people behind it, a more valuable product could be provided.

\section{OPPORTUNITIES FOR ADDITIONAL RESEARCH}

This paper introduces the team health assessment as a tool for measuring user satisfaction as summarised through a series of qualitative questions. The approach is still in its early stages and greater data stands to be produced. In addition to the trends that may present, additional efforts could be made to compare these trends in the team health indices to more traditional lean construction measures, such as PPC, productivity, safety incident rates, total project costs, etc., to identify if any significant correlation exists.

\section{ACKNOWLEDGMENTS}

Our greatest appreciation to DPR Construction in its constant support of continuous improvement - \#EVERFORWARD.

Lessons learned provide greatest value when others could learn from them. 


\section{REFERENCES}

altexsoft. (2019). "Agile project management: Best practices and methodologies." <https://www.altexsoft.com/whitepapers/agile-project-management-best-practicesand-methodologies/>.

Ballard, G. (1999). “Work structuring.” White Paper \# 5, Lean Construction Institute, Las Vegas, Nevada.

Ballard, G. and Howell, G. (2003). "An update on last planner." Proceedings of the 11th Annual Conference of the International Group for Lean Construction. Blacksburg, VA.

Ballard, G. and Zabelle, T. (2000). "Project definition." White Paper \# 9, Lean Construction Institute.

Fowler, M. (2104). "Maturity model.”< https://martinfowler.com/bliki/MaturityModel .html>.

Green, S. (1999). "The dark side of lean construction: Exploitation and ideology" Proceedings of the 7th Annual Conference of the International Group for Lean Construction. Berkeley, CA.

Howell, G. (1999). "What is lean construction?” Proc. of the 7th Ann. Conf. of the Int'l Group for Lean Construction. Berkeley, CA.

Howell, G., Laufer, A., and Ballard, G. (1993). "Interaction between sub cycles: One key to improved methods." Journal of Construction Engineering and Management, ASCE, 119(4).

Izak B., Goldstein, D. and Mead, M. (1987). "The case research strategy in studies of information systems case research." MIS Quarterly, 11(3), 369-386.

Kamata, S. (1982). Japan in the passing lane: An insider's account of life in a Japanese Auto Factory, Pantheon Books, NY.

Kniberg, H. (2104). "Squad health check model - Visualizing what to improve." < https://labs.spotify.com/2014/09/16/squad-health-check-model/>.

McGill, I. and Beaty, L. (1995). Action learning, Kogan Page, London.

Mehri, D. (2006). "The darker side of lean: An insider's perspective on the realities of the Toyota production system." Perspectives - Academy of Management, 20(2), 21-42.

Mossman, A. (2018). "What is lean construction: Another look." Proc. of the 26th Ann. Conf. of the Int'l Group for Lean Construction. Chennai, India.

Revans, R. (1982). The origins and growth of action learning, Chartrell-Bratt, Bromley.

Seed, B. (2010). Transforming design \& construction: a framework for change, Lean Construction Institute, Arlington, VA.

Westbrook, R. (1995). "Action research: a new paradigm for research in production and operations management." International Journal of Operations \& Production Management, 15(12), 6-20.

Womack, J., Jones, D. and Roos, D. (1990). The machine that changed the world, Rawson Associates, NY. 
Muñoz, A., Laurent, J. and Dierks, $C$

\section{APPENDICIES (ABRIDGED)}

1. Spotify Health Check Model

2. Project ABC Actuals

3. Project PSU Actuals 